\title{
Railway Accident Prevention and Infrastructure
}

\section{Protection}

\author{
El-Miloudi El-Koursi and Jean-Luc Bruyelle \\ IFSTTAR (French Institute of Science and Technology for Transport, Development and Networks), Villeneuve 59666, France
}

\begin{abstract}
Railway accident prevention and protection are a key part of a wider picture of transport safety. The rail sector thus needs to improve its knowledge of trespassing and suicide, including at level crossing, in order to work out suitable responses by analyzing measures already taken in various countries. Governments, the rail industry and road organizations have been implementing a variety of countermeasures for many years to improve railway safety. These actions are substantial and have resulted in a continuing decrease in the number and the severity of accidents. This paper presents existing suitable techniques that are used in the preventative measures targeted to reduce railway suicides, trespassing and level crossing user accidents. It describes them in terms of their capability to effectively reduce accidents, their cost-effectiveness and their integration within the railway transport system as a whole.
\end{abstract}

Key words: Railways, safety, infrastructure, level crossing, trespassing.

\section{Introduction}

The rail transport mode is made more effective and efficient by the fact that it connects the most populated areas at increasingly high speeds, providing social cohesion at local level and constituting an important factor in land use planning at the national, European and international levels. The rail sector thus needs to ensure its security against accidents and suicides occurring on its property in order to offer continued service and maximum reliability. An important means to achieve this goal is the analysis of the measures already taken in various countries to address these events. Responses cannot be easily transposed from one country to another as they take into account specific cultural and sociological phenomena; Furthermore, they depend on the socio-political organization of a country and the resultant allocation of responsibilities and competences. This paper describes general preventative measures targeted to reduce railway suicides and trespassing accidents, and it describes

Corresponding author: El-Miloudi El-Koursi, Ph.D., research fields: railway and safety. them in terms of their capability to effectively reduce accidents, their cost-effectiveness and their integration within the railway transport system as a whole.

A particular case is the level crossing, which is the interface between two very different transport modes. Moreover, accidents at level crossings are mostly linked to human errors committed by road users. It is thus difficult to define the responsibilities' borders in this case, and the approaches used to ensure safety are somewhat different from those used at other parts of the railway infrastructure [1-4].

The paper is organized as follows: (1) In Section 2, some relevant statistics on railway safety are presented and analyzed in order to identify the main trends; (2) In Section 3, the measures used to protect railway infrastructure and avoid accidents are presented and discussed; (3) Section 4 details the particular case of level crossings and the specific measures devoted to them; (4) Finally in Section 5, we conclude the study while exposing the main prospects of our work in this field.

\section{Statistics Analysis}

A significant source of information regarding 
railway safety and accidents can be found at the European scale in the European Railway Agency's biennial reports on railway safety performance in the European Union [5], which gives an overview of both the global European situation and of the situation in the various participating countries. Other sources of information are the national authorities, as well as the RUs (railway undertakings) and IMs (infrastructure managers), who publish or allow access to more recent and/or more specific information. For instance, the investigation reports on specific accidents.

In this paper, we will mainly take into account the recent period, covering more specifically the 2010 2012 time-frame. More recent data are not fully available yet, so it is still too early to draw conclusions for the 2013 2014 period.

An important indicator of railway safety is the number of significant accidents, defined as any accident involving at least one rail vehicle in motion, resulting in at least one killed or seriously injured person, or in significant damage (i.e., equivalent to 150,000 euros or more) to stock, track other installations or environment, or extensive traffic disruption. Over the 2010 2012 period, the number of significant accidents has decreased from 2,294 to 2,088, a 9\% drop. At the same time, the total number of fatalities also dropped by $9 \%$, from 1,272 to 1,133 [5].

However, these figures are not homogeneously distributed among all the parts of the network or among all categories of victims. The most frequent accidents are accidents to persons (in which a person is hit by a railway vehicle in motion) followed by accidents at level crossings (in which a road user is hit by a railway vehicle in motion). In 2012, these two categories accounted for $58 \%$, respectively $28 \%$ of the significant accidents, i.e., $86 \%$ of the accidents belonging to these two categories alone. The situation is the same if we consider the number of fatalities (Fig. 1), with 58\% killed in accidents to persons and $33 \%$ at level crossings. More importantly, the longer-term trends depicted in Ref. [5] show that the accidents at level crossings are an exception to the generally decreasing number of fatalities, with a relative stability over the years since 2006. This resistance to mitigation measures, associated to the high number of both significant accidents and fatalities, has drawn considerable attention and effort from stakeholders and researchers to assess the existing measures, analyse the causes of their lack of effectiveness and propose new approaches to level crossing safety.

An important point, as regards fatalities on railways, is the predominance of suicides over accidents. The statistics in Europe show that suicides cause 4.6 times more fatalities than unauthorised person accidents. Moreover, the number of suicides is constantly raising (Fig. 2). This trend is particularly notable in some countries (UK, Sweden, Poland and Lithuania) where the number of suicides increased by $25 \%$ or more on a year-to-year basis. Statistics report suicides separately from accidents (in particular, they are not taken into account in Ref. [5] and Fig. 1), but obviously, the measures and policies aimed at improving railway safety have to take both these aspects into account.

\section{Accidents to Persons: Trespassing and Suicides}

The accidents implying persons out of level crossings, or "accidents to persons", mostly involve

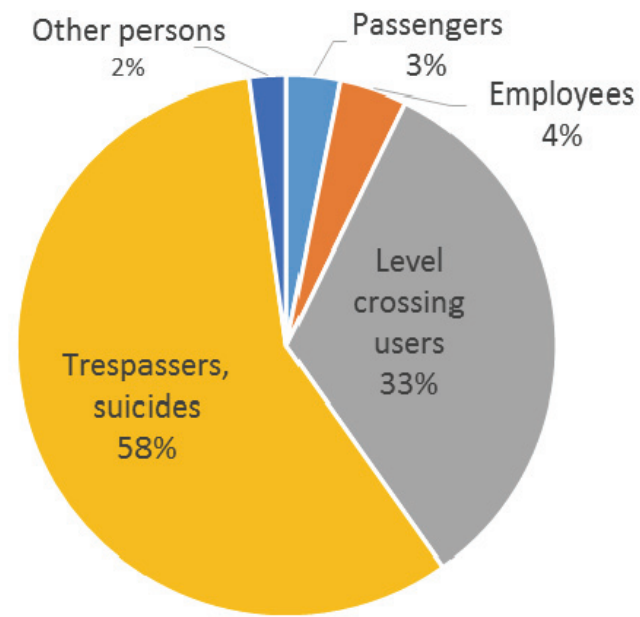

Fig. 1 Number of fatalities per victim category [5]. 


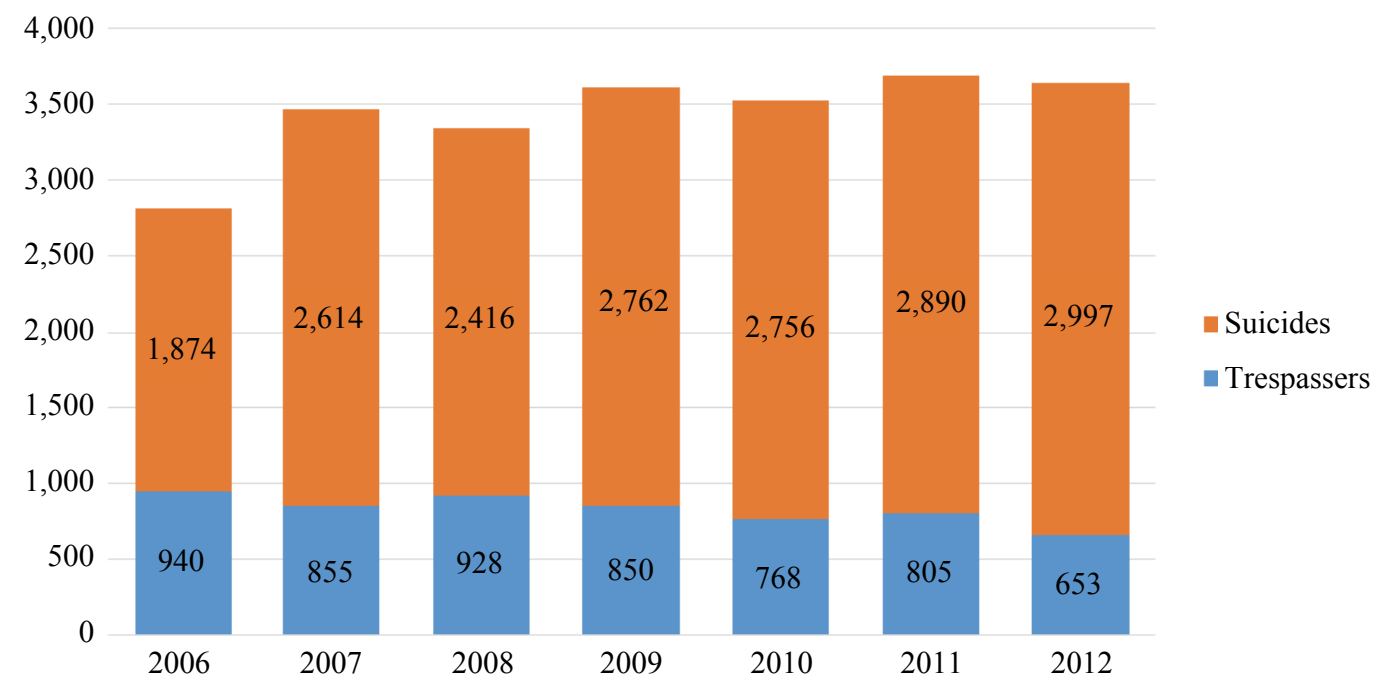

Fig. 2 comparison of unauthorized person fatalities and suicides [5].

unauthorized persons crossing or walking along the tracks, usually out of convenience. Another, much more common as seen above, cause of fatalities and significant accidents out of level crossings is the suicidal intent of persons entering the railway premises to voluntarily be hit by a train. This section aims at clarifying specific and common aspects of trespassing behaviours, with or without suicidal intent, in order to classify the measures aimed to either behaviour and assess their effectiveness.

Based on a review of the state of the art, the RESTRAIL project ${ }^{1}$ has developed an explicit model to account for trespassing with suicidal intent, as well as trespassing with no intent of casualty. This model differentiates between suicidal intent and non-suicidal antecedents to the decision of entering into the track area $[6,7]$. The steps afterwards are common to suicide and trespassing, although the attitudes and behaviours of trespassers in these steps are likely to differ depending on their intent.

The proposed model supports the analysis of the chain of events potentially leading to a collision. In the case of railway collisions, this chain is divided

\footnotetext{
${ }^{1}$ RESTRAIL (REduction of Suicides and Trespasses on RAILway property) is an FP7 project led by UIC, started in 2011 and ended in 2014. Details can be found on the website of the project: http://www.restrail.eu/.
}

into two separate segments, one dealing with suicidal intent and the other with trespassing without suicidal intent, merging into a third common segment in the final stages leading to the collision.

The first motivation to enter the tracks refers to suicide-specific aspects and the associated countermeasures, such as the detection of suicidal intent near the tracks. These measures are dealing specifically with the intent of committing suicide and do not necessarily have any effect on trespassing with no intent of casualty. Another set of suicide-oriented measures aims at reducing the perceived attractiveness and availability of rail traffic as a mean of committing suicide.

The second motivation refers to trespassing behaviours with no intent of casualty, like shortcutting, loitering in railway premises, vandalism, etc. Some measures specifically target the various motivations to trespass: For example, measures targeting metal theft could result in a decrease of associated trespassing events. A second set of measures aims at increasing the knowledge of regulations and risks, as well as on other factors that might influence the decision to trespass. All these measures do not necessarily take the suicide into consideration, so their effects on the latter can be null or even negative. For example, developing measures to increase the knowledge of 
risks could also increase the attractiveness of rail for persons willing to commit suicide.

A third possible antecedent is unintentional trespassing, i.e., situations in which the circumstances result in inadvertently entering the tracks. For example, absent or ambiguous signage, or the absence of lighting at night associated to an unprotected door opening to the tracks might result in unintentional trespassing. Falling or being pushed from the platform is another example of unintentional trespassing.

Finally, for the "common path" corresponding to the final steps before the collision, the associated measures at each step are likely to have a positive effect on both suicide and trespassing situations, although this effect can differ quantitatively and qualitatively. For example, a person attempting to commit suicide would stay on the tracks area whereas other types of trespassers would tend to leave the area once they understand the dangerousness of their act.

It is worth noting that one single measure may have an effect at different steps in the process. As an illustration, fences influence directly the accessibility to the tracks and, at the same time, they direct and support the correct behaviour. However, fences could also influence the perception of the availability of railway to commit suicide, at least in the considered area, which can also contribute to decreasing the number of suicides.

As one of the main consequence of our simplified

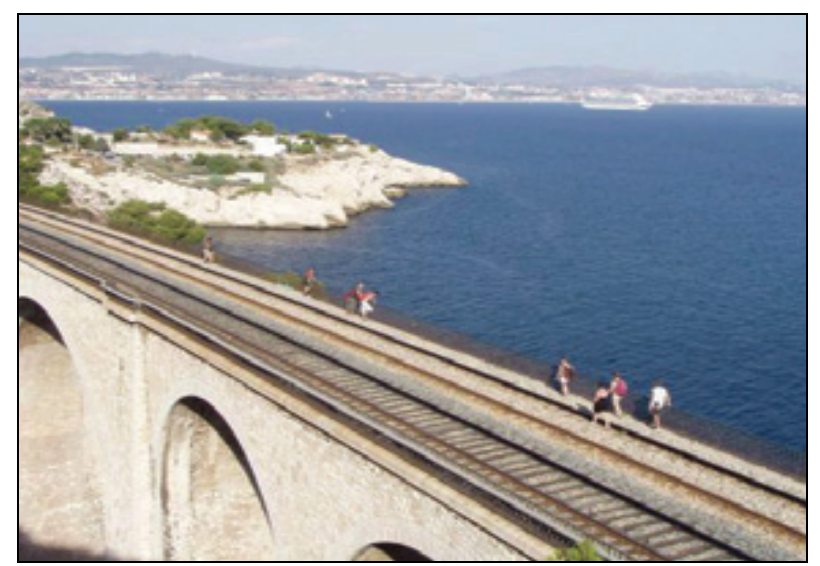

Fig. 3 Trespassers using the rail tracks as a shortcut to the beach. model, measures dedicated to suicide and/or trespassing do not necessarily have an effect limited to one type of incident and can affect both types, either positively or negatively. Applying the model enables us to suggest the following a priori analyses:

- The measures aiming to influence the decision to commit suicide on rail tracks influence the perceived attractiveness and availability railways as a mean for suicide and thus are specific to suicidal behaviour. They do not necessarily have a positive effect on trespassing and can even be counterproductive. For example, limiting or avoiding the report of information regarding suicide and other trespassing fatalities on rail could give the false impression that trespassing is not dangerous;

- The measures specifically designed to address the decision to trespass influence the knowledge of regulations and the awareness of risks and do not necessarily take the issues related to suicide into consideration. Therefore, their effect on the latter can be negative, for instance, by sending the message that crossing the tracks is fatal;

- The measures aiming to influence the first steps common to both suicide and trespassing (decision or act of entering the tracks), corresponding to constraints, guidance or support that avoid these behaviours. These measures aim to direct and support the correct behaviour (e.g., fencing, removal of paths across tracks or prohibitive signs) and to influence the access to tracks (e.g., landscaping). It is thus legitimate to think that these measures have a positive effect both on suicide and trespassing, although not with the same level of efficiency depending on the mechanism underlying the specific measure;

- The measures aiming to influence behaviours or the potential consequences once the person(s) being on the track area (potential and consequences of collision/electrocution) should mostly have a common positive effect on both suicide and trespassing. However, the measures could act differently on suicide and for trespassing due to the specific motives 
and behaviours of persons at risk of suicide and trespassers once they are on the tracks. For example (Fig. 3), trespassers usually try to get off the tracks as quickly as possible when a train is approaching or when they have been spotted.

It is worth noting that some measures have potentially opposing effects. For example, campaigns to raise awareness of rail-related risks can influence positively the adoption of safe behaviours in the population, but they could also have a negative effect by increasing the attractiveness of rail as a means of suicide. Due to the current lack of evidence in the literature, the existence of such effects should be considered as potential rather than demonstrated. Three different cases can be distinguished:

- measures (potentially) having a positive impact on both suicide and trespassing prevention-this does not mean that the effect would be the same, however;

- measures (potentially) having a positive impact on one of the targets (suicide or trespassing) and a (potentially) negative impact on the other target, yielding a cross-over effect;

- measures (potentially) having a positive impact on one of the targets (suicide or trespassing) but no expected effect on the other target.

Measures dedicated to preventing suicide and trespassing accidents can be classified in several ways (Table 1). For example, they can be classified according to their nature, according to the targeted factor(s), according to their expected costs and benefits, and according to their acceptability. RESTRAIL has approached the various measures [6] with the distinctive notions of technical and soft measures, though no formal definition of them was initially available. The next sections present the definition we used and a way of extending these based on the notion of barriers commonly used in high risks industries $[8,9]$.

\subsection{1 “Technical/Physical” Measures}

Technical and physical measures correspond to physical or technological artefacts dedicated to the prevention of trespassing and/or suicides. Such measures typically include preventing entry to the site, monitoring the accesses by video surveillance or other sensors, enhancing the visibility or various ways to deter entry (vocal message, lighting, etc.). The technical measures related to trespassing have been classified into groups as follows:

- measures aiming at increasing the visibility of trains or trespassers;

- surveillance measures. Such measures can integrate the surveillance itself and other techniques, for instance, lighting or loudspeakers, in order to deter or influence the behaviour of possible trespassers;

- fencing and landscaping techniques used either in stations, to make the access to the tracks more difficult or to ease the crossing by safe means, e.g., tunnels or pathways and the associated signage;

- measures related to the design of stations and other locations to influence the movements of people.

\subsection{2 "Soft" Measures}

"Soft" measures encompass measures dedicated to influence knowledge and behaviours by actions, such as communication, training, calls for socially responsible behaviour, legal measures and sanctions. These measures typically include the design and placement of signage and posters $[6,10]$, mass media or local prevention campaigns $[11,12]$, intervention in schools and provision of educational materials, reward or punishment [12], attendance of station staff or security personnel. In the framework of the RESTRAIL project, the soft measures related to suicide and trespassing have been classified into groups as follows (Table 1):

- measures related to population education and communication to the public: education, media guidelines, campaigns, support to staff at risk, etc.;

- outreach support by trained staff;

- emergency information at stations, prohibitive signs, warning signs and posters; 
Table 1 Technical and soft families of measures related to trespassing and suicide.

\begin{tabular}{|c|c|c|c|}
\hline Families/forms of suitable identified measures & Trespassing & Suicide & Technical/soft \\
\hline Increased visibility by lighting at railway crossings, tunnels and hotspots & $\mathrm{T}$ & $\mathrm{S}$ & Technical \\
\hline Increasing visibility through removal of vegetation & $\mathrm{T}$ & $\mathrm{S}$ & Technical/soft \\
\hline Surveillance to deter and prevent incidents: CCTV cameras (fixed or mobile) & $\mathrm{T}$ & $\mathrm{S}$ & Technical \\
\hline Surveillance and light to influence behaviour & $\mathrm{T}$ & $\mathrm{S}$ & Technical/soft \\
\hline Detection system combined with sound warnings & $\mathrm{T}$ & $\mathrm{S}$ & Technical/soft \\
\hline Surveillance to deter (social measure) & $\mathrm{T}$ & $\mathrm{S}$ & Technical \\
\hline Surveillance to deter (technical measure) & $\mathrm{T}$ & $\mathrm{S}$ & Technical \\
\hline CCTV camera cameras/motion detectors, linked to (train) traffic stop warnings & $\mathrm{T}$ & $\mathrm{S}$ & Technical \\
\hline Surveillance based on local intelligence (e.g., from police, health authorities) & - & $\mathrm{S}$ & Soft \\
\hline Targeted campaigns (including shock campaigns) & $\mathrm{T}$ & $\mathrm{S}$ & Soft \\
\hline Education and prevention in schools and outside of school & $\mathrm{T}$ & - & Soft \\
\hline Mass media campaigns & $\mathrm{T}$ & $\mathrm{S}$ & Soft \\
\hline Media guidelines & - & $\mathrm{S}$ & Soft \\
\hline Staff Support (staff at risk of suicide) & - & $\mathrm{S}$ & Soft \\
\hline Additional technologies for train drivers (e.g., spotlights, in-cab CCTV) & $\mathrm{T}$ & $\mathrm{S}$ & Technical \\
\hline Emergency button at unstaffed stations & $\mathrm{T}$ & $\mathrm{S}$ & Technical \\
\hline Training of staff-gatekeeper training & - & $\mathrm{S}$ & Soft \\
\hline Training of staff - general awareness rising & $\mathrm{T}$ & $\mathrm{S}$ & Soft \\
\hline Training of drivers/instructions to drivers & $\mathrm{T}$ & $\mathrm{S}$ & Soft \\
\hline Outreach support by trained staff & - & $\mathrm{S}$ & Soft \\
\hline Design of stations and other locations to influence the movements of people & $\mathrm{T}$ & $\mathrm{S}$ & Technical/soft \\
\hline Design of stations and other locations - aesthetics (colours, lighting, music and other devices) & $\mathrm{T}$ & $\mathrm{S}$ & Technical/soft \\
\hline Fences and barriers at specific parts of stations & $\mathrm{T}$ & $\mathrm{S}$ & Technical \\
\hline Fences and barriers at locations outside stations where people take shortcuts across tracks & $\mathrm{T}$ & $\mathrm{S}$ & Technical \\
\hline Design and landscaping of the railway environment & $\mathrm{T}$ & $\mathrm{S}$ & Technical/soft \\
\hline Suicide pits at stations & - & $\mathrm{S}$ & Technical \\
\hline Emergency information at stations (signs, posters, flyers, information on screens etc.) & $\mathrm{T}$ & $\mathrm{S}$ & Soft \\
\hline Prohibitive signs & $\mathrm{T}$ & - & Soft \\
\hline Warning signs and posters to address trespassing & $\mathrm{T}$ & - & Soft \\
\hline Legal measures & $\mathrm{T}$ & $\mathrm{S}$ & Soft \\
\hline Collaboration between organisations and agencies & $\mathrm{T}$ & $\mathrm{S}$ & Technical/soft \\
\hline Risk assessment (e.g., of stations, special circumstances, at risk groups or individuals) & $\mathrm{T}$ & $\mathrm{S}$ & Technical/soft \\
\hline Monitoring and learning from research and best practice & $\mathrm{T}$ & $\mathrm{S}$ & Soft \\
\hline Local suicide and trespassing prevention plan & $\mathrm{T}$ & $\mathrm{S}$ & Soft \\
\hline
\end{tabular}

- surveillance based on local intelligence from police, health authorities, etc.;

- organisational and safety management measures: local or national collaboration, risk assessment, international best practices and research, prevention plans;

- legal measures.

\section{Level Crossings}

Fig. 4 shows the evolution of level crossing accidents and fatalities over the 2006 2012 period.
With the exception of a peak in 2007 , the trend is stable with an average of one person killed and close to one person seriously injured per day in Europe. In 2012, fatalities at level crossings represented $29 \%$ of the total railways fatalities, but only $1 \%$ of the road fatalities the same year [5].

The particular situation of level crossings, which are at the interface between road and railways, poses a particular problem as regards the management of accidents, which are considered a road-safety issue by the IMs even though they take a large share of the total 


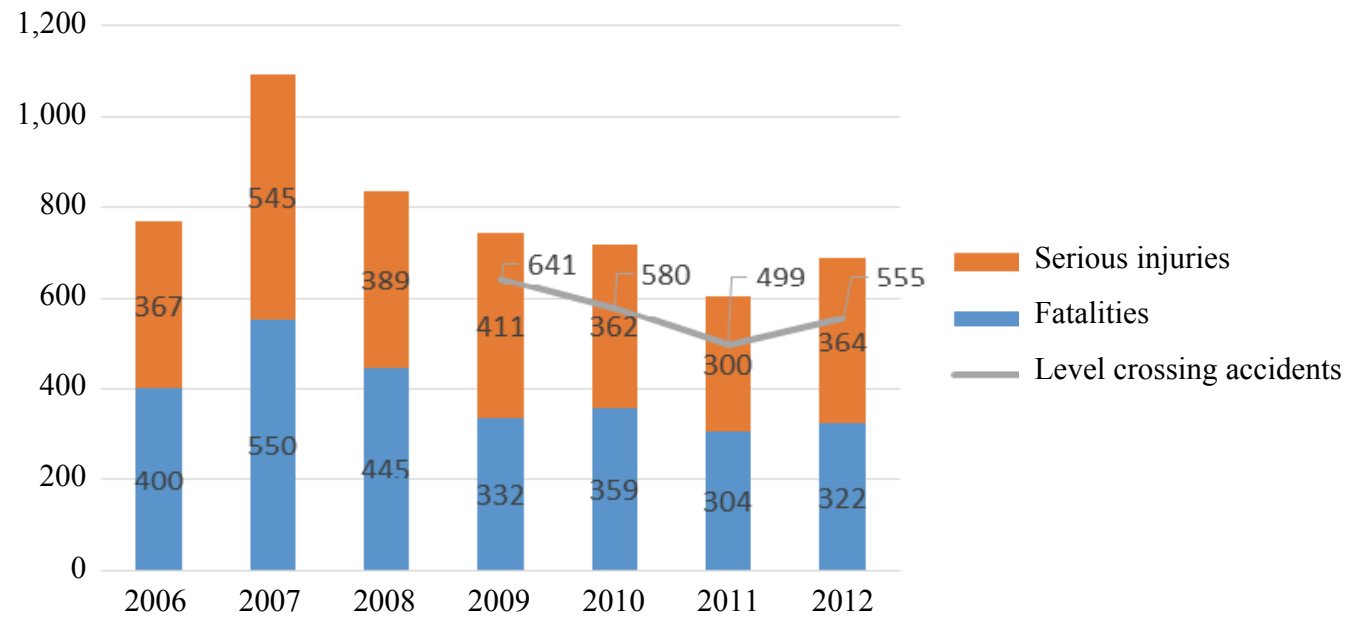

Fig. 4 Level crossing accidents and casualties [5].

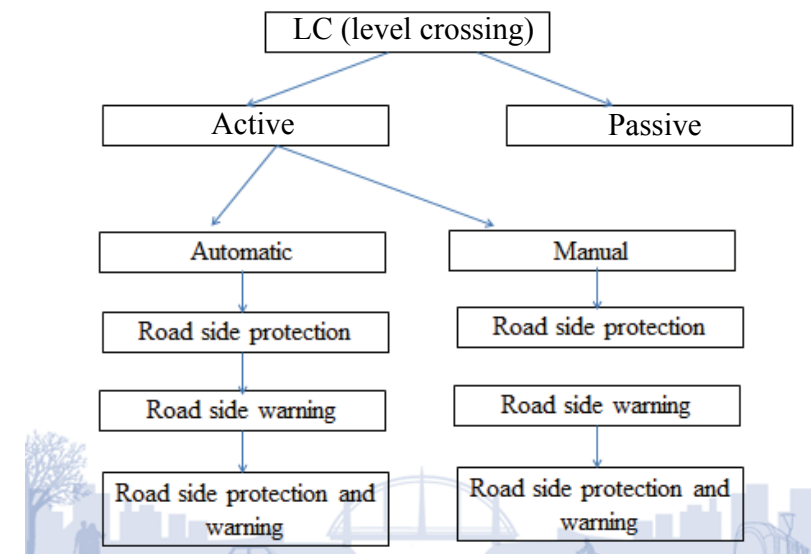

Fig. 5 Level crossings types as classified by ERA (European Railway Agency).

fatalities on railways. In contrast, they represent a minor problem for the authorities in charge of road safety. Another issue is that accidents on level crossings give rise to two separate investigations, one dealing only with the road side and the other focused exclusively on the railway side, which make system-oriented studies all the more difficult since both investigations use utterly different classifications and elements. Studying the safety of level crossings as an entity is, therefore, a difficult task for the researchers.

The European Commission produced in 2004, the Railway Safety Directive [13], in order to define common safety targets and to improve, where possible, the system safety levels. The directive stipulates that member states are duty-bound to conduct an independent investigation in order to improve rail safety and prevent accidents. In addition to serious accidents, the investigating body may conduct investigations into accidents and incidents which, in slightly different circumstances, might have led to more serious accidents, including technical failures in structural sub-sections or interoperability components of the trans-European high-speed or conventional rail system. The Railway Safety Directive requires the safety of railway transport to be defined according to the acceptable individual risks of level crossing users and expects the development of procedures and methods for risk evaluation and assessment. The CST (Common Safety Targets) define the minimum safety levels that must be reached by different parts of the railway system and by the system as a whole in each member state, expressed in risk acceptance criteria for individual and societal risks.

ERA [13] has classified the level crossings into two groups: active and passive (Fig. 5).

A passive level crossing is only equipped with permanent warning signs or any other protection equipment, and it has no form of warning system and/or protection system showing when it is unsafe for the user to traverse the crossing. On the contrary, an active level crossing is equipped with, e.g., lights 
or barriers, to change their configuration when the traffic conditions make crossing dangerous: The level crossing users are protected from, or warned of, the approaching train by the activation of devices when it is unsafe for the user to traverse the crossing. In the case of automatic active level crossings, these devices are activated by the approaching train. Manual active level crossings are activated by humans.

\subsection{Using Advanced Technology to Improve Level Crossings Safety}

The main focus of this section is to describe current and proposed approaches using emerging information technologies to improve the resolution of accident-prone situations on level crossings, which can also be adapted to address situations outside of level crossings to avoid accidents to persons. Such advanced technology can be used to:

- bring technological improvements to the level crossing safety infrastructure, such as the deployment of various types of sensors (audio, video, radar and lasers) for timely detection of potentially hazardous situations;

- use this knowledge to promote human awareness: Situations potentially leading to collisions are treated by sending information via radio networks to approaching railway and road users and prompting suitable behavior in order to avoid the accident. The use of fast, reliable and wireless links enables a seamless communication between the train, car drivers, the level crossing and the main control center.

On the road user side, human awareness can be improved by informing the vehicle drivers of the type of the danger level of the level crossing they are approaching-in particular, inform them of accidents/incidents at level crossings before they get there (Fig. 6). This information will give the road users important cues about the situation that they are going into, in the goal to promote situation awareness and allow early management of incidents, such as finding an alternative route to avoid a jammed level crossing. This information should be presented in a clear and concise way, using advanced technology, such as dynamic panels or short messages on the vehicle built-in displays, in order to avoid cognitive saturation which could in turn cause accidents, instead of avoiding them. A more advanced system could make use of the vehicle's GPS (global position system) to dynamically calculate and propose a new route avoiding the problem and preventing traffic jams.

On the railway side, the information can be sent to the driver's cab as a message that a problem is happening at the next level crossing, along with (if appropriate) the display of the video of the incident. The driver is then able to decide the appropriate action to take in order to avoid the incident. As in the case of road vehicles, caution must be paid to avoid cognitive saturation that might distract the drivers from their main task of driving the train.

It is also envisaged to send the same data (alert message and video/audio stream) to the control center for advanced management and decision making. An important point is to only trigger the sending of such alerts when they appear to become serious, i.e., when the risk of collision is elevated. It has been long established that unnecessarily warning of threats that constantly turn out to be unfounded quickly becomes a nuisance to the operators, and it is both ineffective and dangerous since an actual threat may not be taken

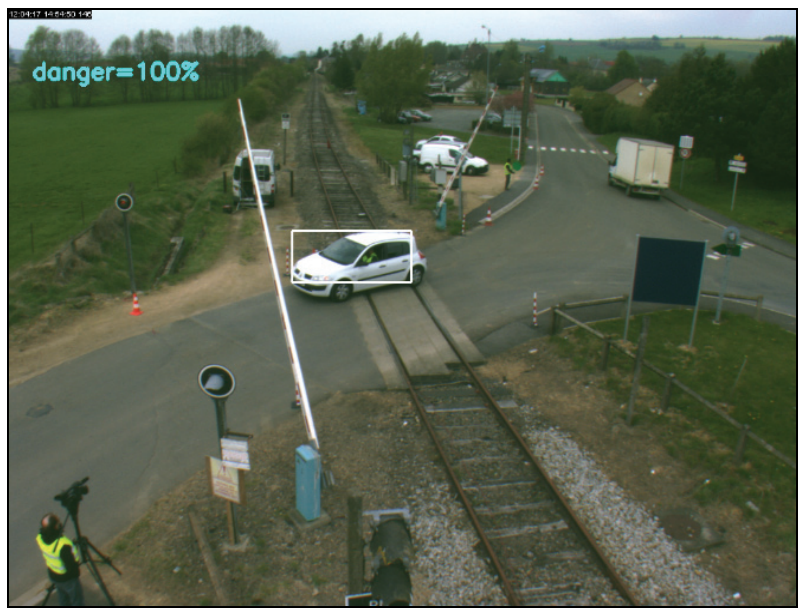

Fig. 6 Automatic detection of a car stopped on a level crossing. 
seriously when it occurs. The robust filtering of such false alarms is not an easy task, and it is a topic of ongoing research.

\subsubsection{Obstacle Detection at Level Crossings}

Most of the level crossings are equipped with signalization, such as red light, automatic full/half barrier, notices, etc. They are not able to avoid all dangerous behaviors. Most of the collisions occurring at level crossings are due to drivers not seeing a train coming or believing that they can beat the train. That is why detection of trapped vehicles/pedestrians inside the barriers, in order to take appropriate action, may reduce the risk of collisions between trains and vehicles. Obstacle detection system seems to be a significant solution to improve level crossing safety and lower the number of fatalities.

An obstacle detection system on level crossing must fulfill the following requirements:

- improvement of the safety for both pedestrians and vehicles (car, truck, motorbike and bicycle);

- no or minimal delays for train and road users;

- accuracy for safety and productivity reasons;

- reasonable condition in terms of costs to install, operate and maintain.

We will first summarize the existing technologies used for object detection at level crossing. Then we will present a test case, based on video imaging and evaluated in life situation.

\subsubsection{Current Detection Technologies}

The detection of a vehicle/pedestrian or other obstacles on the level crossing, when a train is approaching, requires the installation of a detector. Several technologies are capable of doing this, such as optical or sonic sensor, inductive loop, radar and video imaging.

The choice of the appropriate detector can hardly depend on external factors, e.g., environmental conditions or the size of object to detect. Several types of detectors, conventional or newer can be used according to the detection task and operational constraints [14].

\subsubsection{Conventional Detection Systems}

The conventional obstacle detection has been used to prevent crashes between trains and vehicles:

(1) Optical beam: Optical emitters are placed on one part of the crossing, each which emits a directed optical beam having a defined field of emission. If the beams are interrupted, it means that an object is located on the level crossing. Optical beam detectors are easy to replace but they have many important disadvantages: high cost, need for several detectors along the crossing, need to stop the traffic for installation and unusableness in heavy snow;

(2) Sonic detector: The ultrasonic method relies on differences in ultrasonic reflection time. They transmit pulses of ultrasonic energy towards the roadways, which are reflected back quicker when a vehicle passes through. Sonic detectors can detect both stopped and moving vehicles, but they are expensive to purchase and to install and extremely sensitive to the environmental conditions-in particular, they are inaccurate in congested conditions;

(3) Inductive loop: It is probably the most common vehicle detection technology. A wire is embedded under the roadway, generating a magnetic flux around it. A metal-made vehicle passing over the wire cuts the flux, which is detected by the change in inductance. Inductive loops have many advantages: ease of installation and insensitivity to the environmental conditions. But they are costly to install and service, and the traffic must be delayed. Also, they cannot detect pedestrians or bicycles.

\subsubsection{Newer Detection Systems}

Two newer detection systems are introduced as following:

(1) Radar: Microwaves are sent from a transmitter based at the side of the roadway and reflected back to a receiving antenna with a different frequency according to the speed of the reflecting object (Doppler effect). The advantages are easy installation and immunity to electromagnetic interference. However, these sensors are difficult to maintain; 
(2) Video imaging: Video surveillance is one of the newest technologies on level crossings. A camera is placed above the intersection, looking down. The video image is sent by radio to the train driver who can see early whether the intersection is clear and stops on time if not $[15,16]$.

\subsubsection{Automatic Video Detection}

This section is mainly concerned with the timely detection of events that could result in collisions on level crossings. The main purpose of the tools is to detect them when they first happen and it is still time to react and prevent the collision. Examples of such events include a car stopped on the tracks, an object fallen on the tracks or a vehicle unsuccessfully trying to egress a level crossing.

The main aim of automatic video detection is to develop cost-effective and integrated technical solutions able to support pro-active surveillance procedures on a railway network.

Indeed, CCTV (close circuit television) at level crossings can be used for various purposes:

- Off-line use: The perception system is used to produce statistics related to the use of the level crossing and the users' behaviors, automatically detect and identify the abnormal behaviors. This also allows the stakeholders to have quick access to a video sequences and to have a better understanding of the behaviors that led to dangerous situations;

- On-line use: The objective is to identify potentially dangerous situations, such as the presence or approach of objects (pedestrians, motor-cycles, vehicles or other obstacles which could be in the way). In this method, the objective consists in detecting and anticipating a critical situation.

\subsection{Level Crossing Advanced Driver Information System}

Communications between railway stations and railway network elements are vital for uninterrupted and safe operation of railways. Nowadays, data communications provide cost-effective solutions for the data communications and telecommunications needs of the railway industry.

The goal of this section is to compare current situations regarding wireless communications in railway and road exploitation, i.e., CBTC (communication-based train control) and C2I (car-to-infrastructure) communications. On the railway side, CBTC systems, also known as PTC (positive train control) systems, provide positive train separation, speed enforcement and road worker protection using wireless communications to exchange control information. On the road side, based on WLAN (wireless local area network) communications, VANET (vehicular ad-hoc networks) provide distributed real-time communication of traffic hazards and road conditions among vehicles in radio line of sight. These wireless communication systems could then be used to reduce road-rail collisions by communicating information to road vehicles regarding the train movements and the condition of the level crossings.

4.2.1 Train Wireless Communication System

Instead of dedicated telecommunication systems used in the older systems, railway wireless communication systems are now more and more using telecommunication industry existing products, upgraded if necessary. Using such an approach, railway industry takes full advantage of the R\&D investment of the telecommunication industry, cost effective, if compared to the huge telecommunication mass market. Moreover, railway industry takes also benefit of all the telecommunication standards evolutions.

In the telecommunication industry, the first WLAN was introduced in order to substitute for existing conventional wire networks inside buildings. After its initial success, this first objective has been extended to a wide variety of wireless networks that can be named WxAN. They represent different usable levels of compromise between high bit rates and mobility. As such, they are complementary to the cellular network that allows worldwide mobility but a 
restricted bit rate.

\subsubsection{Car Wireless Driver Information System}

As stated before, in a CBTC system, the Railway Local Control Centre and the Main Control Centre are interconnected by bi-directional data communication links which may be wired or wireless. This is not yet the current situation on the road side where only a lateral visual signalization exists, and no distant repetition of the level crossing signaling information is performed inside the vehicles. This situation could evolve in a near future.

In fact, improving traffic efficiency, reducing congestion on roads and reducing accidents, as well as damage cost, are challenging tasks in most regions of the world. To put the problem into context, annual damage cost caused by accidents in the EU (European Union) alone is approximately 100 billion euros. This can be potentially minimized by using new information and communication technologies. Among these technologies, $\mathrm{C} 2 \mathrm{C}$ (car-to-car) and $\mathrm{C} 2 \mathrm{I}$ communications are good candidates to improve the current situation. In this way, connecting vehicles between them or with the infrastructure by a wireless radio link enables a new range of applications and the improvement of existing applications [17].

Using centimetric waves, C2I communications are expected to be operated using omnidirectional and semi directional antennas radiating in a horizontal plane and concentrating energy at low angles over the road surface.

Such a level crossing to vehicle wireless communication could, therefore, provide the repetition of the level crossing signalling information inside the vehicles along a significant communication range. At a mean speed of $60 \mathrm{~km} / \mathrm{h}$, this represents receiving driver warning information $30 \mathrm{~s}$ before arriving in the level crossing area.

\section{Conclusions}

The rail sector needs to ensure its safety against accidents occurring on its property in order to offer continued service and maximum reliability. An important means to achieve this goal is the analysis of the measures already taken in various countries to address these events. This paper describes general preventative measures targeted to reduce railway suicides and trespassing accidents including at level crossings, and it describes them in terms of their capability to effectively reduce accidents, their cost-effectiveness and their integration within the railway transport system as a whole. It discusses the existing countermeasures for reducing suicides, preventing trespasses and mitigating the consequences on rail operations.

\section{References}

[1] Bruyelle, J. L., O’Neill, C., El-Koursi, E. M., Hamelin, F., Sartori, N., and Khoudour, L. 2014. "Improving the Resilience of Metro Vehicle and Passengers for an Effective Emergency Response to Terrorist Attacks." Safety Science (Elsevier) 62: 37-45. doi: 10.1016/j.ssci.2013.07.022.

[2] Fakhfakh, N., Khoudour, L., El-Koursi, E. M., Bruyelle, J. L., Dufaux, A., and Jacot, J. 2011. "3D Objects Localization Using Fuzzy Approach and Hierarchical Belief Propagation: Application at Level Crossings." EURASIP Journal on Image and Video Processing, Special Issue Advanced Video-Based Surveillance, Hindawi 2011: 1-15. doi: 10.1155/2011/548604.

[3] Ghazel, M., and El-Koursi, E. M. 2014. "Two-Half-Barrier Level Crossings Versus Four-Half-Barrier Level Crossings: A Comparative Risk Analysis Study." IEEE Transactions on Intelligent Transportation Systems 15 (3): 1123-33. doi: 10.1109/TI TS.2013.2294874.

[4] Khoudour, L., El-Koursi, E. M., Velastin, S., Buch, N., Lim-Thiebot, S., and Fontaine, F. 2011. "An Approach for Protecting a Critical Transport Infrastructure." In Proceedings of the Institution of Mechanical Engineers, Part F: Journal of Rail and Rapid Transit, Professional Engineering Publishing, 383-93.

[5] ERA (European Railway Agency). 2014. "Railway Safety Performance in the European Union." ERA. Accessed June 18, 2014. http://www.era.europa.eu/Docu ment-Register/Documents/SPR2014.pdf.

[6] Silla, A., Kallberg, V. P., Rådbo, H., Whalley, S., and Ryan, B. 2012. "Summary and Conclusion of D1.1: Data Concerning Railway Suicides and Trespassing Accidents.” RESTRAIL. Accessed June 18, 2014. 
http://restrail.eu/IMG/pdf/restrail-d1-1-281212-summary _and_conclusion.pdf.

[7] Rådbo, H., Svedung, I., and Andersson, R. 2008. "Suicide Prevention in Railway Systems: Application of a Barrier Approach." Safety Science 46: 729-37.

[8] Haddon, W. 1995. "Energy Damage and the 10 Countermeasure Strategies. 1973." Injury Prevention: Journal of the International Society for Child and Adolescent Injury Prevention 1 (1): 40-4.

[9] Hollnagel, E. 2004. Barriers and Accident Prevention. Farnham: Ashgate Publishing, Ltd.

[10] RSSB (Rail Safety and Standard Board). 2006. T555 Improving the Content and Placement of Anti-trespass Signs. Final Report No. T555, Halcrow Group Limited in Partnership with Human Engineering Limited.

[11] Lobb, B., Harre, N., and Suddendorf, T. 2001. "An Evaluation of a Suburban Railway Pedestrian Crossing Safety Programme." Accident Analysis and Prevention 33: 157-65.

[12] Lobb, B., Harré, N., and Nicola, T. 2003. “An Evaluation of Four Types of Railway Pedestrian Crossing Safety Intervention." Accident Analysis and Prevention 35 (4):
487-94. doi: 10.1016/s0001-4575(02)00026-x.

[13] Railway Safety Directive. 2004. "Directive 2004/49/ec of 29 April 2004 on Safety on the Community's Railways and Amending Council Directive 95/18/ec on the Licensing of Railway Undertakings and Directive 2001/14/ec on the Allocation of Railway Infrastructure Capacity and the Levying of Charges for the Use of Railway Infrastructure and Safety Certification." Official Journal of the European Union L220: 16-39.

[14] Little, A. D. 2006. Obstacle Detection at Level Crossing. Research Report T522, RSSB (Rail Safety and Standard Board).

[15] Foresti, G. L. 1998. "A Real-Time System for Video Surveillance of Unattended Outdoor Environments." IEEE Transactions on Circuits and System for Video Technology 8 (6): 697-704.

[16] Ohta, M. 2005. "Level Crossing Obstacle Detection System Using Stereo Cameras.” QR of RTRI 46 (2): 110-17.

[17] The e-Safety Working Group Communications. 2007. Final Report and Recommendations of the Communications Working Group. Brussels: The e-Safety Working Group Communications. 